Departamento de Ciência e Tecnologia, Secretaria de Ciência, Tecnologia e Insumos Estratégicos, Ministério da Saúde

Correspondência | Correspondence: Decit - Departamento de Ciência e Tecnologia do Ministério da Saúde

Esplanada dos Ministérios

Bloco G sala 845

70058-900 Brasília, DF, Brasil

Texto de difusão técnico-científica do Ministério de Saúde.

\section{Atuação do Ministério da Saúde em Ciência e Tecnologia}

\author{
Brazilian Ministry of Health \\ performance on Science \& \\ Technology
}

O Departamento de Ciência e Tecnologia em Saúde (Decit), da Secretaria de Ciência, Tecnologia e Insumos Estratégicos do Ministério da Saúde (SCTIE/MS), atua no sentido de aproximar o fazer científico do universo de tomada de decisão e formulação de políticas públicas pelos gestores da saúde.

Não obstante os avanços alcançados, a crença de que muitas das ações desenvolvidas podem ser aprimoradas e que ainda há muito por fazer motivou a realização do "Decit + 2: atuação do Ministério da Saúde em ciência, tecnologia e inovação". Dois anos depois da realização da $2^{\mathrm{a}}$ Conferência Nacional de Ciência, Tecnologia e Inovação em Saúde, considerou-se fundamental promover um diálogo com as instituições parceiras do Decit, com os gestores da área de saúde e de ciência e tecnologia e com a comunidade científica. A perspectiva era de avaliar o trabalho desenvolvido ao longo desses dois anos, definir mecanismos de institucionalização do fomento à pesquisa no Ministério da Saúde e apontar futuros caminhos de atuação.

O evento reuniu cerca de 280 pessoas entre representantes da comunidade científica e gestores da área da saúde e da ciência e tecnologia. Na oportunidade, além do III Encontro Nacional do Programa Pesquisa para o SUS (PPSUS) e das oficinas que integraram o I Encontro Nacional de Redes de Pesquisa e Estudos Multicêntricos em Saúde, foram realizados debates e mesas-redondas que contaram com a presença de especialistas que puderam avaliar a atuação do Decit e trazer contribuições.

Com o intuito de possibilitar uma avaliação ainda mais completa e, sobretudo, com um olhar externo ao Departamento, foi solicitado que alguns desses especialistas produzissem um documento utilizando os relatórios anuais de gestão como insumos. Os pontos relevantes analisados estão a seguir.

Rita Barradas Barata, Professora da Faculdade de Ciências Médicas da Santa Casa de São Paulo, produziu um documento baseado na Política Nacional de Ciência, Tecnologia e Inovação em Saúde, modelo adotado também pelo Departamento em suas apresentações e relatórios, uma vez que essa Política norteia todas as suas ações. A estratégia que mereceu mais destaque por parte da avaliadora foi o Fortalecimento do Esforço Nacional em Ciência, Tecnologia e Inovação em Saúde, destacando a importância da ampliação das fontes de financiamento, potencializada a partir do acordo de cooperação firmado com o Ministério da Ciência e Tecnologia em 2004. Do mesmo modo, foi ressaltado também as parcerias instituídas com os estados por meio das fundações de amparo à pesquisa, secretarias estaduais de saúde e secretarias estaduais de ciência e tecnologia que representaram o aporte de recursos novos para a área. $\mathrm{O}$ incentivo à formação de redes $\mathrm{e}$ de estudos multicêntricos também foi considerado uma importante iniciativa nessa estratégia.

Apesar de ter sido incluído nessa estratégia, o PPSUS também apresenta forte componente da estratégia de superação das desigualdades regionais. Criado em 2004, o PPSUS surgiu a partir uma iniciativa anterior, quando o Decit transferia recursos às fundações de amparo à pesquisa dos estados com menor capacidade instalada de pesquisa em saúde. Simultaneamente, estimulava a constituição de núcleos ou assessorias de ciência e tecnologia em saúde no âmbito das secretarias estaduais de saúde. A criação do Programa possibilitou a ampliação da iniciativa para todos os estados que desejassem participar. Até 2006, todos os estados brasileiros já tinham sido contemplados com pelo menos um edital do PPSUS.

$\mathrm{Na}$ estratégia que prevê a criação de um Sistema Nacional de Inovação, Rita Barata destacou algumas ações como o financiamento de projetos na área de desenvolvimento e produção de equipamentos médicos, medicamentos, vacinas e métodos diagnósticos. No entanto, ela observou que ainda não foi possível articular esse sistema, sugerindo que essa deve ser uma das metas a perseguir incisivamente nos próximos anos. 
Uma estratégia na qual o Decit tem avançado bastante, segundo a avaliadora, é o aprimoramento da capacidade regulatória do Estado. Rita Barata afirmou que a necessidade de desenvolver a capacidade de gestão de tecnologia no interior do SUS foi percebida, desde a criação do Decit, destacando a criação do Grupo de Trabalho em Avaliação de Tecnologias em Saúde em 2003 e, no ano seguinte, o estabelecimento da parceria entre o Departamento e o Centro Cochrane para a realização de revisões sistemáticas e metanálises. Essas ações têm se tornado cada vez mais uma prioridade do Decit, que instituiu uma Coordenação-geral de Avaliação de Tecnologias em Saúde em 2005. Em 2006, novas medidas foram adotadas: o estabelecimento de diretrizes técnico-operacionais, definindo fluxos e formulários para a solicitação de estudos, além de critérios de priorização e, a elaboração da proposta de Política Nacional de Gestão de Tecnologias em Saúde.

Como principal desafio, Rita Barata apontou a institucionalização do papel que o Ministério da Saúde (MS) passou a exercer. Segundo ela, a não criação de uma agência de fomento da pesquisa em saúde com autonomia administrativa, subordinada ao MS torna o exercício deste papel de liderança sujeito às instabilidades decorrentes da falta de continuidade observada historicamente com relação às políticas públicas no País. A idéia de que é necessário articular essa institucionalização é compartilhada por Cristovam Picanço, Professor da Universidade Federal do Pará, que também foi consultado sobre a atuação do Departamento.

Após traçar um panorama geral da Ciência e Tecnologia em Saúde no contexto mundial, Picanço iniciou ressaltou que é difícil medir com acuidade o impacto das ações desenvolvidas num período tão curto. Também destacou que o ano de 2004, em particular, marcou uma mudança substantiva na forma de agir do Departamento. A forma de atuar em parceria com as agências de fomento trouxe, segundo o consultor, maior eficiência para o Decit na aplicação dos recursos e agilidade na execução dos orçamentos, que puderam ser aplicados em sua maior proporção nas atividades-fim. Um outro aspecto que o consultor considerou importante foi o investimento nas várias regiões do País e a integração de ações nacionais induzidas a partir de editais contemplando redes de pesquisa, destacando que se cumpriu o princípio de respeitar na maioria dos editais, percentual mínimo de $30 \%$ dos recursos alocados nacionalmente para as regiões Norte, Nordeste e Centro-Oeste.

José da Rocha Carvalheiro, Presidente da Associação Brasileira de Pós-graduação em Saúde Coletiva, dividiu a sua análise em três etapas: os objetivos, o método e os resultados. De uma forma sintética, apresentou não apenas uma avaliação, mas uma provocação, a partir de questionamentos e sinalizações. Ao final do documento, defendeu que o Decit está "no caminho certo" e, concordando com os demais consultores, sugeriu que o próximo objetivo a ser percorrido será consolidação e institucionalização das ações desenvolvidas.

Luís Eugênio Portela Fernandes de Souza, representante do Conselho Nacional de Secretários Municipais de Saúde (CONASEMS) apresentou a perspectiva de um gestor municipal de saúde, traçando um paralelo com as novas atribuições da gestão municipal no desenho da política nacional de saúde. Foi por ele ressaltada a significativa expansão dos recursos investidos em Ciência e Tecnologia (C\&T) em saúde, o apoio à constituição às redes de pesquisa e o fortalecimento das estruturas estaduais de investigação (secretarias estaduais de saúde e fundações de amparo à pesquisa).

Como outros pontos importantes cumpridos, o consultor salientou a criação do Sistema Nacional de Inovação em Saúde e o papel central de articulação do Ministério da Saúde, reforçando a parceria com o setor de C\&T; superação das desigualdades regionais; aprimoramento da capacidade regulatória do Estado; aproximação do esforço de pesquisa das necessidades de saúde da população e divulgação científica para os gestores e profissionais de saúde. Entretanto, sem descurar de apontar o muito que se tem por fazer, assinalou a premência de revisão da agenda de prioridades, reduzindo-se a fragmentação de temas e melhorando o sistema de monitoramento, ademais do aperfeiçoamento das medidas positivas indicadas anteriormente. No campo da gestão municipal, não se furtou a reconhecer que habitualmente o gestor municipal, premido pelas urgências do seu cotidiano, descura das questões de C\&T, caracterizando-se pelo consumo passivo de informações e tecnologias postas em circulação por outros agentes sociais. Daí, a busca de um novo papel para o gestor municipal (e estadual), em que o mesmo tenha participação ativa na definição das prioridades de pesquisa e engajamento na produção, incorporação e difusão de novos conhecimentos científicos, que aperfeiçoem a prática cotidiana dos cuidados e práticas de saúde.

O Departamento considerou a avaliação dos especialistas um importante instrumento para subsidiar no planejamento e em decisões futuras, sempre no sentido de progredir ainda mais naquilo que já vem sendo realizado e priorizar outras frentes onde ainda há muito que fazer. A recomendação dos consultores de trabalhar arduamente no sentido de institucionalizar as ações realizadas pelo Ministério da Saúde por meio do Decit, é um sentimento e uma aspiração compartilhada por parte significativa dos atores envolvidos com a ciência e tecnologia em saúde no Brasil, e a prioridade número um do Departamento. Isso porque um plano estratégico de longo prazo, imprescindível para consolidar todo o esforço realizado ao longo dos anos e tornar menos vulneráveis os resultados já alcançados, 
requer considerável autonomia em relação à agenda das lideranças políticas.

A partir do conjunto dessas avaliações e do cotejamento com os objetivos institucionais do Decit, é possível au- gurar que os próximos anos deverão ser palco de um cenário positivo de consolidação desta relação produtiva entre pesquisadores e gestores, instrumentalizada pelo Decit, e mais amplamente pela Secretaria de Ciência, Tecnologia e Inovação do Ministério da Saúde. 